\title{
Symptoms of pituitary apoplexy rapidly reversed with bromocriptine
}

\section{Case report}

\section{Michael H. Brisman, M.D., Gillian Katz, M.D., and Kalmon D. Post, M.D.}

Departments of Neurosurgery and Endocrinology, The Mount Sinai Medical Center, New York, New York

Macroprolactinomas rarely present with apoplexy. The authors describe a patient with a macroprolactinoma who presented with apoplexy and rapid progression of a third nerve palsy. The patient was managed expectantly with bromocriptine therapy, and within 48 hours, the patient's third nerve palsy had completely resolved. The authors suggest that all patients who present with pituitary apoplexy in the presence of a pituitary tumor receive an immediate course of bromocriptine and steroid therapy until the prolactin level can be determined. Emergency surgery is indicated if visual function is abnormal and the tumor is not a prolactinoma.

Key Words * prolactinoma * bromocriptine * third nerve palsy * apoplexy * cavernous sinus * pituitary

Macroprolactinomas most often present with endocrinological abnormalities, visual disturbances, or headaches, and the initial treatment is usually a dopamine agonist such as bromocriptine.

Macroprolactinomas rarely present with acute deterioration resulting from apoplexy; treatment in these cases is not well defined. It is not clear exactly how severe and rapidly progressing the symptoms should be to mandate an emergency surgical decompression or an initial trial of bromocriptine therapy.

We describe a patient with a macroprolactinoma who presented with pituitary apoplexy and a rapidly progressing third nerve palsy. We report the first well-described case of pituitary apoplexy treated successfully with bromocriptine therapy and the first case of an oculomotor palsy to resolve within 48 hours of its administration.

\section{CASE REPORT}

This 44-year-old man presented to medical attention because of 4 days of rapidly progressive drooping of his left eyelid and double vision; this was accompanied by headaches, nausea, dizziness, and blurring of vision in his left eye. A computerized tomography scan of the head at another hospital had shown a large sellar/suprasellar tumor. The patient was started on an intravenous course of dexamethasone $4 \mathrm{mg}$ every 6 hours, and the next day he was transferred to our institution. On admission, the patient noted a 
headache and some dizziness. He reported that vision had been somewhat worse in his left eye over the past 4 years, but that he had had no visual difficulty prior to this current episode when he wore his glasses. He denied any other medical problems including sexual dysfunction. He reported worsening of his diplopia and ptosis, even after the steroid administration.

Examination. On examination, the patient was alert and oriented. Ophthalmological examination revealed that there was $80 \%$ ptosis of the left eyelid. There was a marked impairment of left eye adduction and elevation and a mild impairment of depression. The left eye was significantly more myopic than the right, but acuity with corrective lenses was 20/20 in the right eye and 20/30 in the left. Pupils were equal in size and briskly reactive to light. There was an afferent pupillary defect in the left eye, a superior visual field defect, and a central red temporal defect. The remainder of the physical examination was normal.

Contrast-enhanced magnetic resonance imaging of the head was performed emergently and demonstrated a $3.5 \times 4 \times 6-\mathrm{cm}$ sellar/suprasellar tumor, expanding the sella and encasing both carotid arteries (Fig. 1). The results of full endocrinological testing were as follows: prolactin, $7650 \mathrm{ng} / \mathrm{ml}$ (normal $0-20 \mathrm{ng} / \mathrm{ml}$ ); cortisol, $3.4 \mu \mathrm{g} \%$ (normal 5-25 $\mu \mathrm{g} \%$ ); somatomedin C, $362 \mathrm{ng} / \mathrm{ml}$ (normal 123-463 ng/ml); T4-RIA, 6.2 $\mu \mathrm{g} \%$ (normal 4.5-12.5 $\mu \mathrm{g} \%$ ); T3-RIA, $130 \mathrm{ng} \%$ (normal 100-200 ng\%); TBG-RIA, $24.4 \mu \mathrm{g} / \mathrm{ml}$ (normal $14.5-32 \mu \mathrm{g} / \mathrm{ml}$ ); T4/TBG, $2.5 \mathrm{mg} \%$ (normal 2.5-6.5 mg\%); thyroid-stimulating hormone-3rd generation, $0.34 \mu \mathrm{IU} / \mathrm{ml}$ (normal 0.2-5 $\mu \mathrm{IU} / \mathrm{ml}$ ); follicle-stimulating hormone, $0.96 \mathrm{mIU} / \mathrm{ml}$ (normal $1.5-14 \mathrm{mIU} / \mathrm{ml}$ ); luteinizing hormone, $1.1 \mathrm{mIU} / \mathrm{ml}$ (normal $1.4-7.7 \mathrm{mIU} / \mathrm{ml}$ ). The patient was started on a course of $2.5 \mathrm{mg}$ bromocriptine every 8 hours. Plans to surgically debulk the tumor were made if symptoms continued to progress.

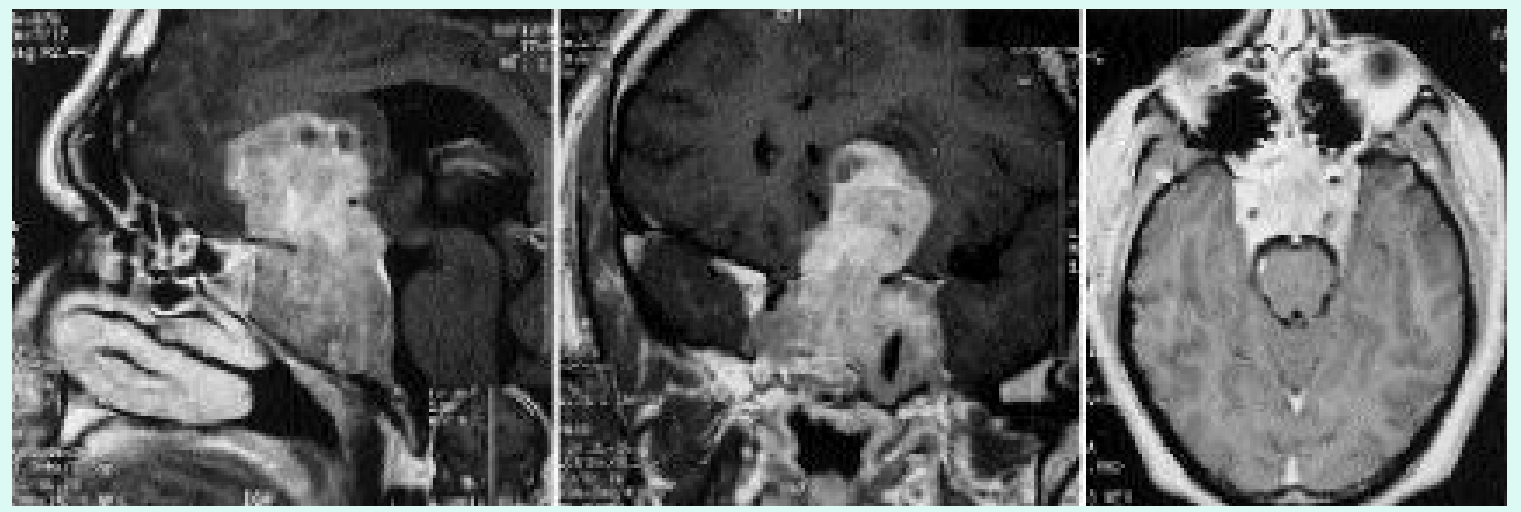

Fig. 1. Magnetic resonance T1-weighted contrast-enhanced imaging, sagittal (left), coronal (center), and axial (right) views demonstrating a very large sellar/suprasellar tumor expanding the sella and encasing both carotid arteries.

After one dose of bromocriptine adduction and elevation in the patient's left eye were better and his ptosis was less marked (30\%-40\%). After 48 hours of treatment, his third nerve palsy had completely resolved and he felt well. Initial endocrinological testing was significant for a prolactin level of 7650 $\mathrm{ng} / \mathrm{ml}$ ( normal , $20 \mathrm{ng} / \mathrm{ml}$ ), a testosterone level of less than $20 \mathrm{ng} / \mathrm{dl}$ (normal 300-1000 ng/dl), and slight decreases in levels of luteinizing hormone and follicle-stimulating hormone. The prolactin level after 1 day of bromocriptine treatment was $1048 \mathrm{ng} / \mathrm{ml}$, and after 3 days of treatment it was $180 \mathrm{ng} / \mathrm{ml}$. Two weeks after treatment was initiated magnetic resonance imaging revealed marked reduction in the size of the tumor to $3 \times 4 \times 5 \mathrm{~cm}$ (Fig. 2). After 1 month the patient's testosterone level was $153 \mathrm{ng} / \mathrm{dl}$, and after 3 months, his prolactin level was $47 \mathrm{ng} / \mathrm{ml}$. Currently, his extraocular movements and visual fields are normal. 


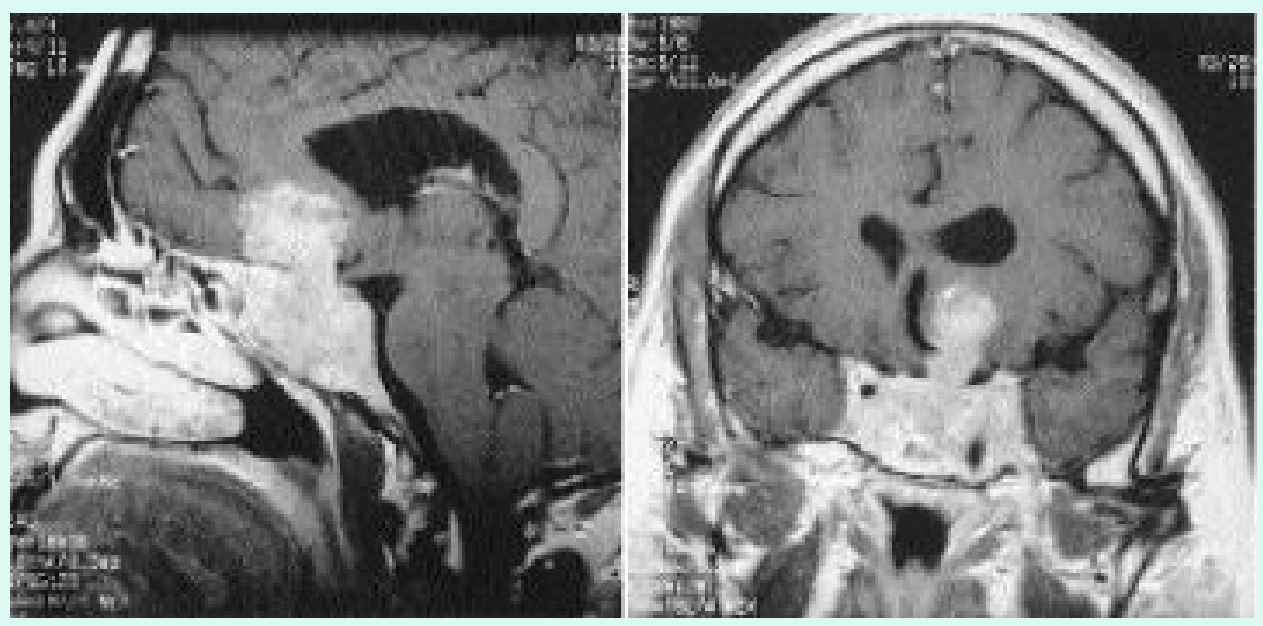

Fig. 2. Magnetic resonance T1-weighted contrast-enhanced imaging, sagittal (left) and coronal (right) views, 2 weeks after initiation of bromocriptine treatment demonstrating marked reduction in the size of the tumor.

\section{DISCUSSION}

Pituitary apoplexy is a clinical syndrome related to an acute mass expansion around the pituitary gland. Apoplexy is characterized by a sudden onset of symptoms which include severe headache, nausea, vomiting, visual impairment, ophthalmoplegia, pituitary dysfunction, and sometimes, altered mental status and death. Apoplexy is attributed to the development of acute necrosis or hemorrhage within a pituitary tumor, or sometimes, within the normal pituitary gland. Standard treatment consists of immediate initiation of high-dose steroids and surgical decompression, if symptoms are severe or rapidly progressive.

When pituitary tumors manifest acutely with apoplexy, which has been reported to occur in $1 \%$ to $9 \%$ of pituitary tumors, ocular palsies are a common feature, ranging from $16 \%$ to $69 \%$, depending on the series. $[6,8,9,14]$ A third nerve palsy is the most common ocular palsy to occur with pituitary apoplexy, $[6,8,9]$ and, as in our case, pupillary function is often spared.

Hemorrhage and necrosis probably are not such rare occurrences in pituitary tumors, including prolactinomas, $[10,12,15]$ but a clinical picture of apoplexy is less common. When apoplexy does occur, the course can be quite variable and unpredictable, ranging from symptoms of headache alone to death. When ocular palsy is present, improvement will frequently occur with surgery or steroid treatment alone, although improvement is not universal, is usually gradual, and is often not complete.[1,8]

Standard treatment of apoplexy includes: immediate initiation of high-dose steroid treatment, which can improve symptoms of apoplexy, sometimes in as little as a few days, [2,5,7,11] and surgical decompression, usually via a transsphenoidal route, if symptoms are considered "severe" or "rapidly progressive." Exactly how severe or rapid symptoms should be to mandate an operation is not particularly well defined.

Bromocriptine therapy is the standard treatment for prolactinomas. It has been reported to improve visual acuity in as few as 2 days. [4,13] This is the first reported case of the resolution of a third nerve palsy within 48 hours of initiation of medical therapy. The ability of bromocriptine to reduce mass effect in prolactinomas rapidly and to restore function of compressed structures suggests that it may be helpful for some patients with apoplexy who have underlying prolactinomas. 
Because prolactinomas are a common type of pituitary adenoma, it is not surprising that quite a few patients with pituitary apoplexy have prolactinomas, $12 \%$ to $38 \%$ depending on the series. $[1,6,9]$ At the time of apoplexy presentation, however, it is often not known if the tumor is a prolactinoma, because apoplexy is usually the first manifestation of the tumor[3] and serum prolactin levels are usually not instantly available.

In our case, the patient complained of worsening ocular motor symptoms despite steroid treatment. He was started on a course of bromocriptine before prolactin levels were available, and after one dose, began to rapidly improve. We are aware of no other nonsurgical treatment, with or without steroid administration, that has been reported to reverse an ocular palsy so quickly and completely.

We recommend that patients presenting with apoplexy and a pituitary tumor be immediately started on a course of bromocriptine and steroid treatment, until prolactin levels are available. Emergency surgery should still be considered for visual dysfunction.

\section{References}

1. Ahmed M, Rifai A, Al-Jurf M, et al: Classical pituitary apoplexy presentation and a follow-up of 13 patients. Hormone Res 31:125-132, 1989

2. Armstrong MR, Douek M, Schellinger D, et al: Regression of pituitary macroadenoma after pituitary apoplexy: CT and MR studies. Case report. J Comput Assist Tomogr 15:832-834, 1991

3. Cardoso ER, Peterson EW: Pituitary apoplexy: a review. Neurosurgery 14:363-373, 1984

4. Chiodini P, Liuzzi A, Cozzi R, et al: Size reduction of macroprolactinomas by bromocriptine or lisuride treatment. J Clin Endocrinol Metab 53:737-743, 1981

5. Dawson BH, Kothandaram P: Acute massive infarction of pituitary adenomas. A study of five patients. J Neurosurg 37:275-279, 1972

6. Ebersold MJ, Laws ER, Scheithauer BW, et al: Pituitary apoplexy treated by transsphenoidal surgery: a clinicopathological and immunocytochemical study. J Neurosurg 58:315-320, 1983

7. Hutchinson DO, Avery SF: Pituitary apolexy. NZ Med J 102:158-160, 1989

8. McFadzean RM, Doyle D, Rampling R, et al: Pituitary apoplexy and its effect on vision. Neurosurgery 29:669-675, 1991

9. Onesti ST, Wisniewski T, Post KD: Clinical versus subclinical pituitary apoplexy: presentation, surgical management, and outcome in 21 patients. Neurosurgery 26:980-986, 1990

10. Ostrov SG, Quencer RM, Hoffman JC, et al: Hemorrhage within pituitary adenomas: how often associated with pituitary apoplexy syndrome? AJR 153:153-160, 1989

11. Sachdev Y, Gopal K, Garg VK, et al: Pituitary apoplexy (spontaneous pituitary necrosis). Postgrad Med J 57:289-293, 1981

12. Symon L, Mohanty S: Haemorrhage in pituitary tumors. Acta Neurochir 65:41-49, 1982

13. Thorner MO, Martin WH, Rogol AD, et al: Rapid regression of pituitary prolactinomas during 
bromocriptine treatment. J Clin Endocrinol Metab 51:438-445, 1980

14. Wakai S, Fukushima T, Teramoto A, et al: Pituitary apoplexy: its incidence and clinical significance. J Neurosurg 55:187-193, 1981

15. Wilson CB: A decade of pituitary microsurgery. The Herbert Olivecrona Lecture. J Neurosurg 61:814-833, 1984

Manuscript received May 30, 1996.

Accepted in final form June 17, 1996.

Address reprint requests to: Michael H. Brisman, M.D., Department of Neurosurgery, The Mount Sinai Medical Center, 1 Gustave Levy Place, New York, New York 10029. 